\title{
Effect of Strain Rate on the Mechanical Properties of Crystallized Poly(L-lactide)*
}

\author{
Shusaku YAMADI** and Satoshi KOBAYASHI*** \\ ** Graduate Student, Tokyo Metropolitan University \\ 1-1 Minami-Osawa, Hachioji, Tokyo, Japan \\ E-mail: syusaku.yamaji@nifty.com \\ *** Graduate School of Science and Engineering, Tokyo Metropolitan University
}

\begin{abstract}
In this study, effects of strain rate on the mechanical properties of injection-molded poly(L-lactide) (PLLA) were investigated experimentally. The effect of crystallinity on the strain rate dependency of mechanical properties of PLLA was also examined by annealing the specimens at 70 and $130{ }^{\circ} \mathrm{C}$ for 24 hours. In order to characterize the mechanical properties, tensile and compressive tests were conducted. The results of tensile tests indicate that the Young's modulus kept constant up to strain rate of $10^{-1}$. On the other hand, tensile strength of non-annealing, $70^{\circ} \mathrm{C}-24 \mathrm{~h}$ and $130^{\circ} \mathrm{C}-24$ specimens increased with increasing strain rates up to $10^{-1}, 10^{-2}$ and $10^{-3}$, respectively, and decreased or kept constant because of decrease in the fracture strain with increasing strain rate. The effect of strain rate became lower with increasing crystallinity, which means the strain rate dependency of the PLLA under tensile loading is more effective in the amorphous region. The results of compressive tests indicate that the compressive Young's modulus kept constant up to strain rate of $10^{-1}$. On the other hand, $0.2 \%$ proof stress increased with increasing strain rate. This tendency was similar to the tensile test.
\end{abstract}

Key words: Poly(L-lactide), Strain Rate, Crystallinity, Amorphous

\section{Introduction}

Bioresorbable fracture fixations made of poly(L-lactide) PLLA are drawing attention as a substitute material for metallic device due to non-necessity of second surgery, and applied in clinical setting. PLLA is a polymeric L-lactic acid existing in the body and bioresorbable plastics. Now, various studies for PLLA in medical approach have been conducted on the drag delivery system (DDS), suture, bioabsorbable scaffold, and fracture fixations. In the past, various in vitro and in vivo properties evaluations had conducted ${ }^{(1-4)}$. Migliaresi et al. conducted immersion tests in Ringer's solution on PLLA with various molecular weights. They presented that the initial molecular weight of PLLA with 177,000 decreased into 32,000 and kept its mechanical properties after 327 days immersion ${ }^{(1)}$. Pistoner et al. conducted in vivo experiments. They could not measure the mechanical properties because of the degradation of the crystallized and amorphous PLLA after 72 and 90 weeks respectively ${ }^{(2)}$. Almost those evaluations, however, have been carried out at low strain rate (about $10^{-4} / \mathrm{s}$ ). In the actual usage, it is expected that fracture fixations are subject to dynamic or impact loading, such as $10^{0} \sim 10^{1} / \mathrm{s}$. PLLA is a polymeric material. Generally, mechanical properties of polymeric material are strongly influenced by strain rate ${ }^{(5,6)}$. Therefore, it is necessary to evaluate the mechanical properties of PLLA at higher strain rates. 
In this study, effects of strain rate on the mechanical properties of PLLA were investigated. In order to reveal the strain rate dependency of PLLA, the PLLA specimen was prepared by injection molding. The effect of crystallinity on the strain rate dependency of PLLA was also examined to anneal the specimens at 70 and $130{ }^{\circ} \mathrm{C}$ for 24 hours. Tensile and compressive tests were performed to evaluate the mechanical properties. This type of studies were considered to provide a guideline for material design of bioabsorbable fracture fixations.

\section{Materials and method}

\subsection{Preparation of Poly (L-lactide) specimens}

Lacty\#5000 (Shimazu Co., Ltd., Kyoto, Japan) was used as Poly (L-lactide) (PLLA) in preparation. PLLA pellets were dried at $70^{\circ} \mathrm{C}$ for 4 hours before molding. PLLA specimens $(100 \mathrm{~mm} \times 10 \mathrm{~mm} \times 4 \mathrm{~mm})$ were fabricated using an injection molding machine (NP7 Real Mini, Nissei Plastic Industrial Co., Ltd., Nagano, Japan). The molding conditions were listed in Table $1^{(7)}$. In the mold, a single gate was located at the end of the specimen. The specimens fabricated were annealed at 70 and $130{ }^{\circ} \mathrm{C}$ for 24 hours with a hot press system and cooled at room temperature. Non-annealed and annealed at 70 and $130^{\circ} \mathrm{C}$ specimens are abbreviated as non-annealing, $70^{\circ} \mathrm{C}-24 \mathrm{~h}$, and $130^{\circ} \mathrm{C}-24 \mathrm{~h}$ specimens, respectively.

Table 1 Molding conditions.

\begin{tabular}{c|c}
\hline Mold clamping force $/ \mathrm{kN}$ & 69 \\
\hline Injection pressure $/ \mathrm{MPa}$ & 136 \\
\hline Fusion temperature $/{ }^{\circ} \mathrm{C}$ & 210 \\
\hline Mold temperature $/{ }^{\circ} \mathrm{C}$ & 50 \\
\hline Cooling time $/ \mathrm{s}$ & 30 \\
\hline
\end{tabular}

\subsection{Crystallinity measurement}

Crystallinity of specimens was measured with a differential scanning calorimeter (DSC), (DSC-60, Shimadzu Co., Ltd., Kyoto, Japan). 3 6mg DSC samples were cut out from the specimens. The samples were heated at using a heating rate of $10^{\circ} \mathrm{C} / \mathrm{min}$ up to $230{ }^{\circ} \mathrm{C}$ in the air. The crystallinity of specimens $\left(X_{c}\right)$ were calculated as follows

$X_{c}=\frac{\Delta H_{m}+\Delta H_{c}}{\Delta H_{100 \%}} \times 100$

where $\Delta H_{c}$ is the crystallization enthalpy, $\Delta H_{m}$ and $\Delta H_{100 \%}$ are the enthalpy of melting of PLLA samples and PLLA crystal having infinite crystal thickness. We used $135 \mathrm{~J} / \mathrm{g}$ as $\Delta H_{100 \%}{ }^{(8)}$.

\subsection{Tensile tests}

The specimens for tensile tests were polished using the 180 and 800 grit abrasive papers in order to obliterate the imprints of the extruded rods. The specimen size was $100 \mathrm{~mm} \times$ $10 \mathrm{~mm} \times 4 \mathrm{~mm}$, as molded. Then aluminum tabs were glued on the end of the specimen to avoid the stress concentration. In order to measure strain, strain gauges were bonded on the both side of the specimen. Tensile tests were conducted at room temperature using a universal testing machine (Autograph AG-IS 50kNE, SHIMAZU Co., Ltd., Kyoto, Japan) and an electro-hydraulic high-speed material tensile test system (V-1505, Saginomiya, Inc., Tokyo, Japan) at testing rate of $1-1000 \mathrm{~mm} / \mathrm{min}$ and $0.1-1 \mathrm{~m} / \mathrm{s}$, respectively. After the 
tensile tests, the fracture surfaces of the specimens were observed with a scanning electron microscope (SEM) (S-2500CX, Hitachi, Ltd., Tokyo, Japan).

\subsection{Compressive tests}

The specimens with $10 \mathrm{~mm} \times 10 \mathrm{~mm} \times 4 \mathrm{~mm}$ in geometry were cut from the injection-molded specimens for the compressive tests. The upper and lower surfaces were polished using 180 and 800 grit abrasive papers in order to collimate these surfaces. In order to measure strain, strain gauges were bonded both sides of the specimens. Compressive tests were conducted at room temperature using a universal testing machine (Autograph AG-IS 50kNE, Shimadzu Co., Ltd., Kyoto, Japan) at testing rate of 1-1000 $\mathrm{mm} / \mathrm{min}$.

\section{Results and discussion}

\subsection{Crystallinity of PLLA specimens}

Figure 1 shows crystallinity of PLLA specimens with three different annealing conditions. The $X_{c}$ value of non-annealing specimens was $2.75 \%$. This denotes that non-annealing specimens are also amorphous. $X_{c}$ increased with increasing annealing temperature, $X_{c}$ of 70 and $130^{\circ} \mathrm{C}-24 \mathrm{~h}$ specimens were 27.32 and $47.33 \%$, respectively.

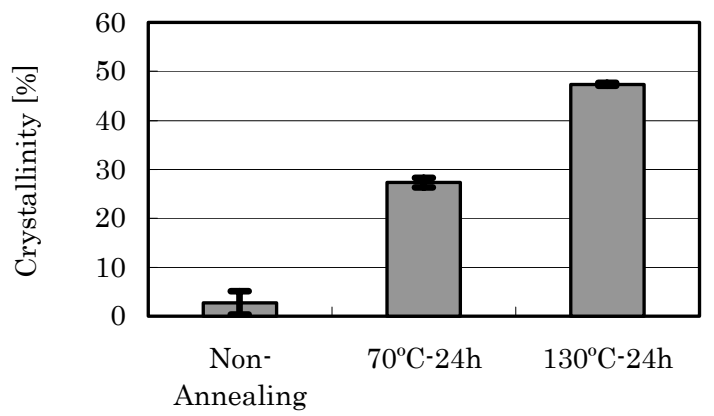

Annealing condition

Figure 1 Crystallinity of PLLA with annealing conditions.

\subsection{Results of tensile tests}

Figure 2 shows tensile stress-strain curves for PLLA specimens over a range of strain rates. In all specimens, the strain for nonlinear behavior initiation increased with increasing strain rate. Tensile strength also increased with increasing strain rate. Additionally, in non-annealing specimens, fracture strain decreased significantly with increasing strain rate. On the other hand, fracture strain of $130^{\circ} \mathrm{C}-24 \mathrm{~h}$ specimens increased with increasing strain rate. It is considered to involve the 3-dimentional stress state of amorphous PLLA around the spherulite, which is the toughening mechanism of the polymeric materials ${ }^{(8)}$. The mechanism in detail will be discussed in the future work. In the late of loading at strain rate of $10^{1} / \mathrm{s}$, stress-strain curves were disturbed because of the reflected stress waves. So the tensile strength at $10^{1} / \mathrm{s}$ was not evaluated properly and was not considered in the following.

Figure 3 shows the Young's modulus and tensile strength for PLLA specimens over a range of strain rates. Young's modulus of $130^{\circ} \mathrm{C}-24 \mathrm{~h}$ specimens which have highest crystallinity denoted highest value, and those of non-annealing and $70^{\circ} \mathrm{C}-24 \mathrm{~h}$ specimens denoted similar values each other at strain rate of $10^{-4} / \mathrm{s}$. And all specimens denoted approximately constant values up to strain rate of $10^{-1} / \mathrm{s}$. However, those modulus increased 
with increasing strain rate at strain rate of $10^{\circ} / \mathrm{s}$. The tensile strength of $70^{\circ} \mathrm{C}-24$ specimens was the highest value at strain rate of $10^{-4} / \mathrm{s}$, and the strength of $130^{\circ} \mathrm{C}-24 \mathrm{~h}$ specimens were lowest. In all types of specimens, strengths increased with increasing strain rate up to strain rate of $10^{-1} / \mathrm{s}$, and kept constant at strain rate of more than $10^{-1} / \mathrm{s}$.

As noted above, in non-annealing specimens, the decrease in fracture strain was confirmed. In 70 and $130^{\circ} \mathrm{C}-24 \mathrm{~h}$ specimens with higher crystallinity, however, the decrease in fracture strain, was not observed. These results were consistent with the result, where the increase in the toughness was observed under impact load in crystallized PLLA ${ }^{(6)}$.

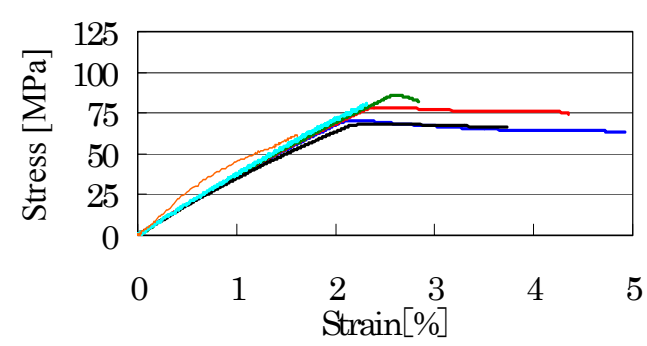

(a) Non-annealing

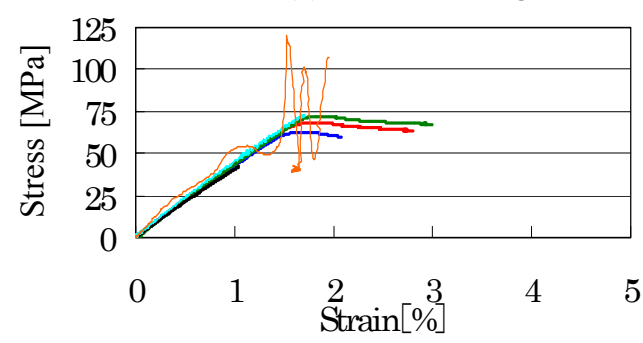

(c) $130^{\circ} \mathrm{C}-24 \mathrm{~h}$

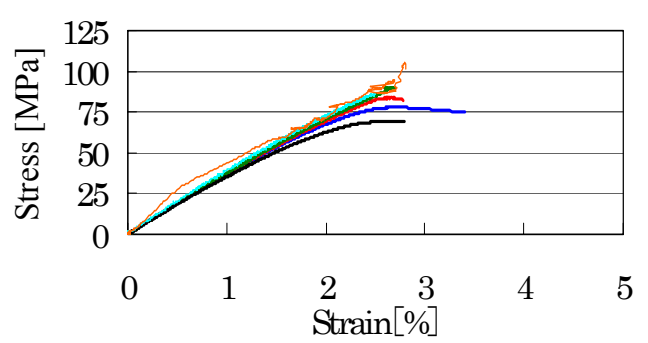

(b) $70^{\circ} \mathrm{C}-24 \mathrm{~h}$

Figure 2 Tensile stress-strain curves of PLLA specimens with strain rates.

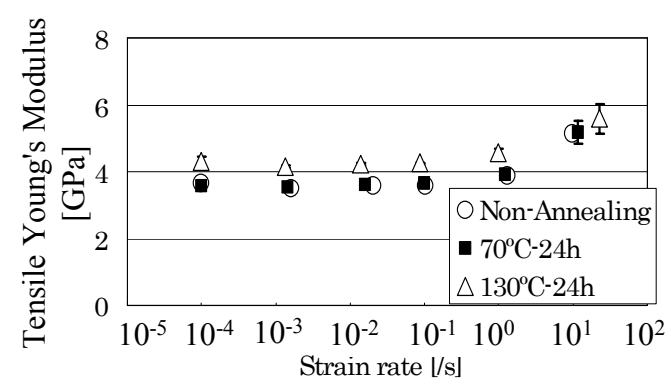

(a) Modulus of Elasticity

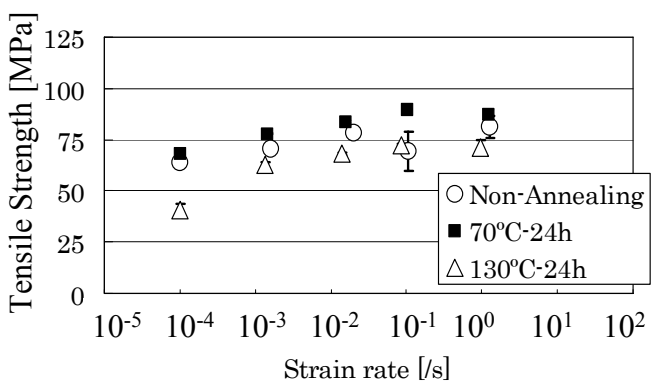

(b) Strength

Figure 3 The results of tensile tests of PLLA specimens with strain rates.

Figure 4 shows the fracture surfaces of non-annealing specimens after tensile tests observed with a SEM. Fig. 4 (b), (d), and (f) were enlargements of fig. 4 (a), (c), and (e), respectively. On the fracture surface at higher strain rate (Fig. 4 (c)), flat plane, which was considered as an origin of the fracture, was observed clearly. In the enlargement images, the fibrils of PLLA, which indicated generation of the craze, was observed at each strain rates, but the number of fibrils decreased with increasing strain rate.

Figure 5 shows the fracture surfaces of $70^{\circ} \mathrm{C}-24 \mathrm{~h}$ specimens after tensile tests observed with a SEM. Two different types of area were observed in the fracture surfaces of $70^{\circ} \mathrm{C}-24 \mathrm{~h}$ specimens. One is the area which include the fibrils of PLLA (Fig. 5 (a), (c), and (e)). In the other area, few fibrils but the dotted-like structures, which correspond spherulite, was observed (Fig. 5 (b), (d), and (f)). And the number of observed fibrils decreased with increasing strain rate. 
Figure 6 shows the fracture surfaces of $130^{\circ} \mathrm{C}-24 \mathrm{~h}$ specimens after tensile tests observed by SEM. Similar to the $70^{\circ} \mathrm{C}-24 \mathrm{~h}$ specimens, two different types of area were observed in the fracture surfaces of $130^{\circ} \mathrm{C}-24 \mathrm{~h}$ specimens. Few fibrils were observed and fracture type is intergranular. This is due to the higher crystallinity of PLLA, which results in the brittle fracture.

As noted above, in the non-annealing specimens, the craze induced higher fracture strain and ductile fracture surface at low strain rates. The crack formation became more dominant than craze formation with increasing strain rate. Therefore, it is considered that fracture morphology became more brittle with increasing strain rate. In the 70 and $130^{\circ} \mathrm{C}-24 \mathrm{~h}$ specimens, as mentioned above, crack formation around the crystalline region was more effective on the fracture behavior over a range of strain rate. Therefore, comparing to non-annealing specimens, tensile strength did not decrease with increasing strain rate.

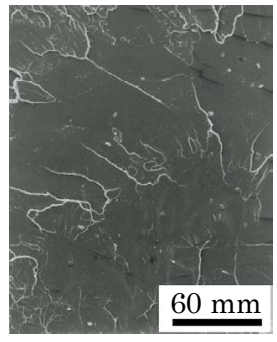

(a) $10^{-3}[/ \mathrm{s}]$

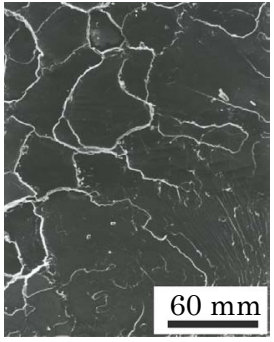

(e) $10^{0}[/ \mathrm{s}]$

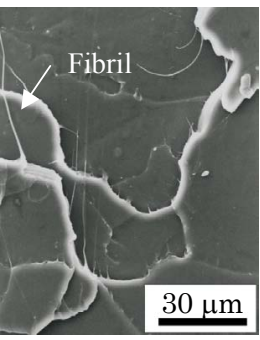

(b) $10^{-3}[/ \mathrm{s}]$

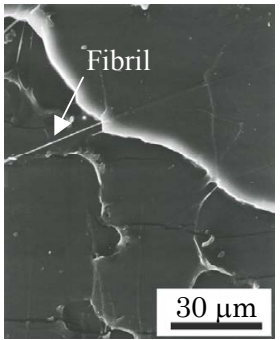

(f) $10^{0}[/ \mathrm{s}]$

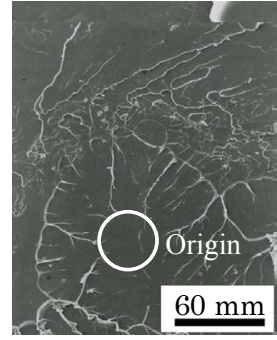

(c) $10^{-2}[/ \mathrm{s}]$

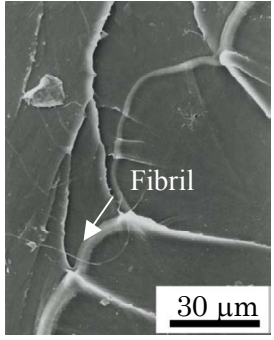

(d) $10^{-2}[/ \mathrm{s}]$

Figure 4 Fracture surface of non-annealing specimens observed by scanning electron microscopy.

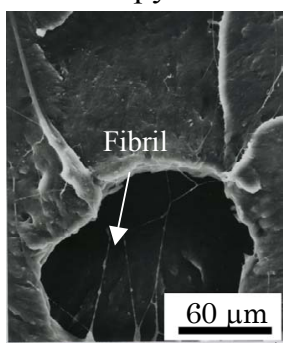

(a) $10^{-3}[/ \mathrm{s}]$

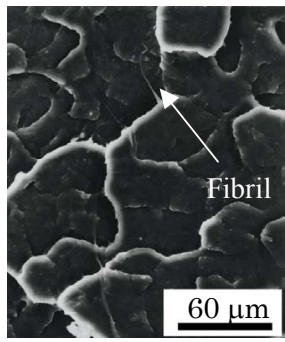

(e) $10^{0}[/ \mathrm{s}]$

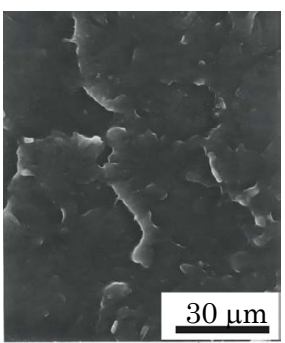

(b) $10^{-3}[/ \mathrm{s}]$

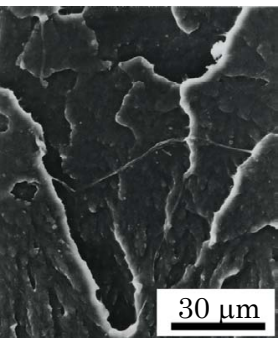

(f) $10^{0}[/ \mathrm{s}]$

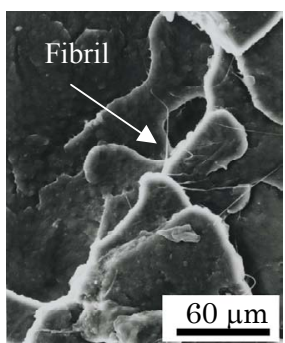

(c) $10^{-2}[/ \mathrm{s}]$

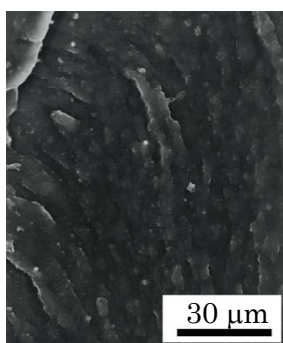

(d) $10^{-2}[/ \mathrm{s}]$

Figure 5 Fracture surface of $70^{\circ} \mathrm{C}-24 \mathrm{~h}$ specimens observed by scanning electron microscopy. 


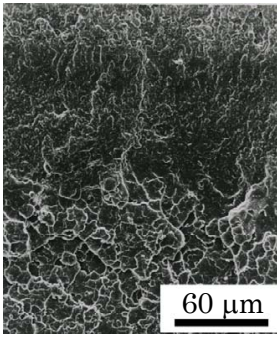

(a) $10^{-3}[/ \mathrm{s}]$

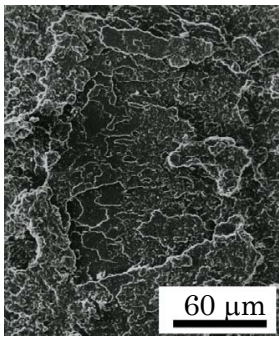

(e) $10^{0}[/ \mathrm{s}]$

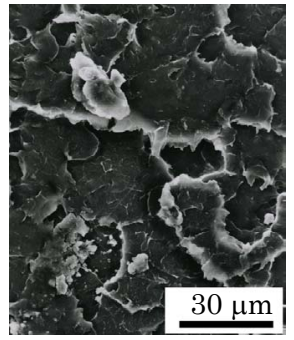

(b) $10^{-3}[/ \mathrm{s}]$

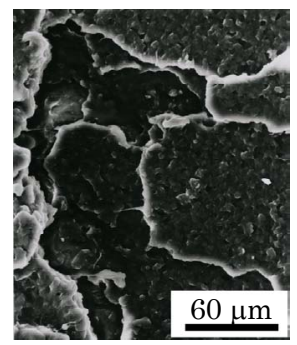

(f) $10^{0}[/ \mathrm{s}]$

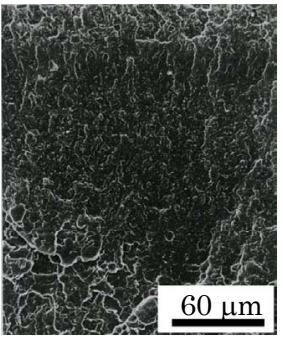

(c) $10^{-2}[/ \mathrm{s}]$

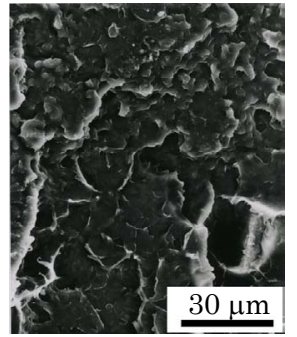

(d) $10^{-2}[/ \mathrm{s}]$

Figure 6 Fracture surface of $130^{\circ} \mathrm{C}-24 \mathrm{~h}$ specimens observed by scanning electron microscopy.

\subsection{Results of compressive tests}

Figure 7 shows compressive stress-strain curves for PLLA specimens over a range of strain rates. In all specimens, the strain for nonlinear behavior initiation increased with increasing strain rate. This tendency corresponded with that of tensile test. The stress-strain curves for non-annealing and $70^{\circ} \mathrm{C}-24 \mathrm{~h}$ specimens at strain rate of $10^{-4} / \mathrm{s}$ showed strain-softening behavior. On the other hand, the other specimens (especially at higher strain rates) did not show this behavior. All specimens deformed in the barrel shape and squashed perfectly.

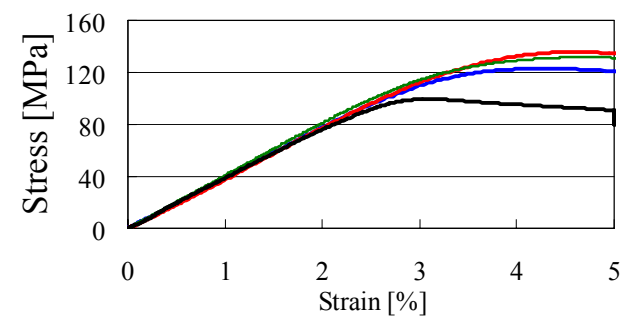

(a) Non-annealing

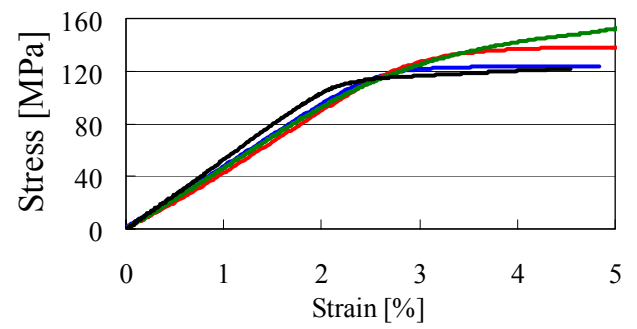

(c) $130^{\circ} \mathrm{C}-24 \mathrm{~h}$

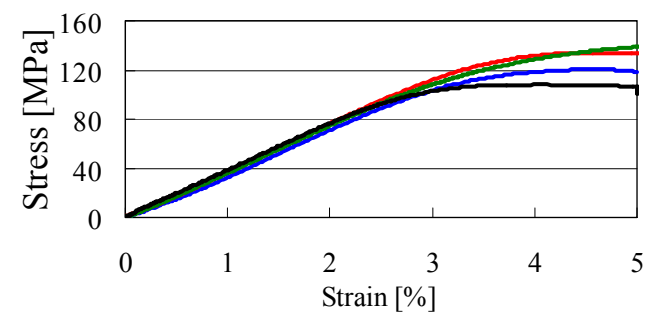

(b) $70^{\circ} \mathrm{C}-24 \mathrm{~h}$

$$
-10^{-4}[/ \mathrm{s}]-10^{-2}[/ \mathrm{s}
$$$$
-10^{-3}[/ \mathrm{s}]-10^{-1}[/ \mathrm{s}]
$$

Figure 7 Compressive stress-strain curve of PLLA specimens with strain rates.

Figure 8 shows the compressive Young's modulus and $0.2 \%$ proof stress for PLLA specimens over a range of strain rates. Compressive Young's modulus of $130^{\circ} \mathrm{C}-24 \mathrm{~h}$ specimens at each strain rates showed the highest value and the modulus of non-annealing and $70^{\circ} \mathrm{C}-24 \mathrm{~h}$ specimens showed similar values each other. No dependency on strain rate 
were observed for compressive Young's modulus up to strain rate of $10^{-1} / \mathrm{s} .0 .2 \%$ proof stress of all specimens showed similar values each other and the values increased with increasing strain rate.

As observed above, the increase in strain rates yielded the increase in $0.2 \%$ proof stress with increasing strain for nonlinear behavior initiation. And, in compressive test, there were no difference between each specimen on strain rate dependency. The similar values of $0.2 \%$ proof stress of each specimen indicated that the $0.2 \%$ proof stress is attributed to yield in amorphous region of PLLA under compressive loading.

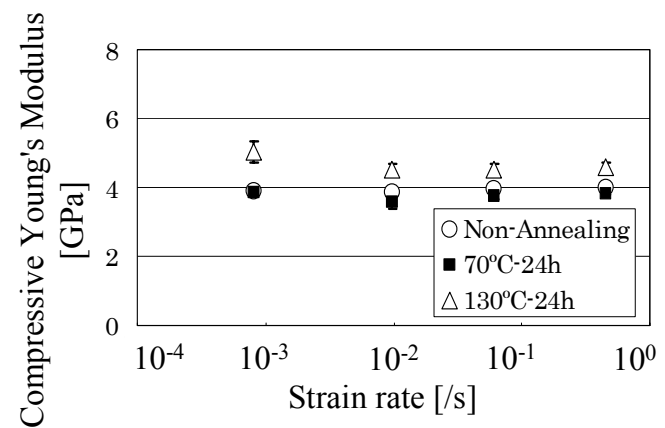

(a) Modulus of Elasticity

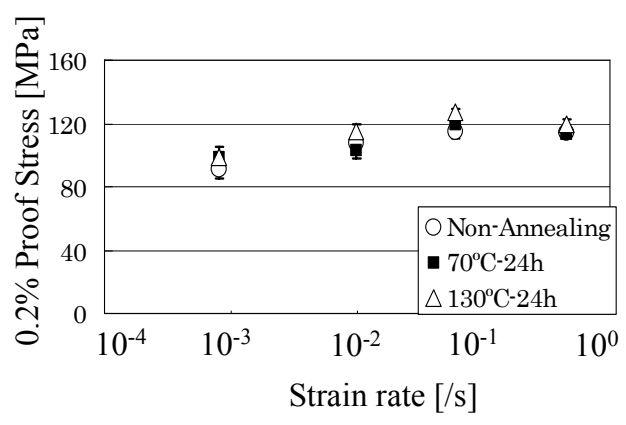

(b) Strength

Figure 8 The results of compressive tests of PLLA specimens with strain rates.

\section{Conclusions}

PLLA specimens were prepared by injection molding, and the tensile and compressive tests were performed up to test speed $1 \mathrm{~m} / \mathrm{s}$. The strain rate dependency of the mechanical properties of PLLA specimens was evaluated experimentally. We obtained the results as follows,

1. In the tensile tests, the highest Young's modulus observed on the $130^{\circ} \mathrm{C}-24 \mathrm{~h}$ specimens with high crystallinity, while lowest tensile strength was also observed for the specimens because of low fracture strain caused by crystallization. In all specimen, the strain for nonlinear behavior initiation and tensile strength increased with increasing strain rate. The modulus increased over the strain of $10^{\circ} / \mathrm{s}$.

2. From the fracture surface examination of the non-annealing specimens, the craze induced higher fracture strain and ductile surface at low strain rates. And then, the crack formation became more dominant than the generation of the craze with increasing strain rate. Therefore, it is considered that fracture morphology became more brittle with increasing strain rate. In the fracture surface of the 70 and $130^{\circ} \mathrm{C}-24 \mathrm{~h}$ specimens, crack formation around the crystalline region was more effective on the fracture behavior. Therefore, comparing to the non-annealing specimens, brittle fracture behavior with increasing strain rate did not decrease the tensile strength with increasing strain rate.

3. In the compressive tests, the highest Young's modulus observed on the $130^{\circ} \mathrm{C}-24 \mathrm{~h}$ specimens with high crystallinity. $0.2 \%$ proof stress was similar value for all types of specimens and increased with increasing strain rate. This tendency corresponded with that of tensile test.

\section{References}

(1) Migiaresi, C., Fambri, L. and Cohn, D., A study of the in vitro degradation of poly (lactic acid), J. Biomater. Sci. Polymer Edn, Vol. 5 (1994), pp. 591-606.

(2) Pistner, H., Stallforth, H., Gutwald, R., Mühling, J., Reuther J. and Michel, C., Poly (L-lactide): a long-term degradation study in vivo Part II. Physico-mechanical behavior of implants, Biomaterials, Vol. 15 (1994), pp. 439-450. 
(3) Pistner, H., Bendix, D. R., Mühling J. and Reuther, J. F., Poly (L-lactide): a long-term degradation study in vivo Part III. Analytical characterization, Biomaterials, Vol. 14 (1993), pp. 291-298.

(4) Duek, E. A. R., Zavaglia, C. A. C. and Belangero, W. D., In vitro study of poly (lactic acid) pin degradation, Polymer, Vol. 40 (1999), pp. 6465-6473.

(5) Chen, W., Lu, F. and Cheng, M., Tension and compression tests of two polymers under quasi-static and dynamic loading, Polymer Testing, Vol. 21 (2002), pp. 113-121.

(6) Park, S. D., Todo, M., Arakawa K. and Koganemaru M., "Effect of crystallinity and loading-rate on mode I fracture behavior of poly(lactic acid)", Polymer, Vol. 47 (2006), pp. 1357-1363.

(7) Kobayashi, S. and Todo, M., The effect of hydrolysis on the mechanical properties of injection-molded poly(L-lactic acid), Journal of Solid Mechanics and Materials Engineering, Vol. 2 (2008), pp. 8-14.

(8) Tsuji, H., Daimon, H. and Fujie, K., A New Strategy for Recycling and Preparation of Poly (L-lactic acid): Hydrolysis in the Melt, Biomacromolecules, Vol. 4 (2003), pp. 835-840.

(9) Ishikawa, M., Stability of plastic deformation and toughness of polycarbonate blended with poly(acrylonitrile-butadiene-styrene), Polymer, Vol. 36 (1995), pp. 2203-2210. 